\title{
Patients with pheochromocytoma exhibit low aldosterone renin ratio-preliminary reports
}

Tomoko Yamada', Hidenori Fukuoka ${ }^{\text {* }}$ D, Yusei Hosokawa ${ }^{1}$, Yukiko Odake ${ }^{2}$, Kenichi Yoshida², Ryusaku Matsumoto², Hironori Bando', Yuko Okada', Yushi Hirota', Genzo Iguchi', Wataru Ogawa² and Yutaka Takahashi

\begin{abstract}
Background: Plasma renin activity (PRA) is generally increased in patients with pheochromocytoma (PCC) due to low circulating plasma volume and activation of $\beta-1$ adrenergic receptor signaling. However, there has been no study on the aldosterone renin ratio (ARR) in patients with PCC. To elucidate the issue, this study aimed to determine the PRA, plasma aldosterone concentration (PAC), and ARR in patients with PCC and compare them with those in patients with subclinical Cushing's syndrome (SCS) and non-functioning adrenal adenoma (NFA).

Methods: In this retrospective single-center, cross-sectional study, 67 consecutive patients with adrenal tumors (PCC $(n=18)$, SCS $(n=18)$, and NFA $(n=31))$ diagnosed at Kobe University Hospital between 2008 and 2014 were enrolled.

Results: PRA was significantly higher in patients with PCC than in those with SCS and NFA (2.1 (1.3 2.8) vs. 0.7 (0.5 1.8) and $0.9(0.6 \sim 1.4) \mathrm{ng} / \mathrm{mL} / \mathrm{h} ; p=0.018$ and $p=0.025)$. Although PACs were comparable among the three groups, ARR was significantly lower in patients with PCC than in those with SCS and NFA (70.5 (45.5 79.5) vs. 156.0 (92.9 194.5) and 114.9 (90.1 153.4); $p=0.001$ and $p<0.001$ ). Receiver operating characteristic curve analysis demonstrated that, in differentiating PCC from NFA, PRA $>1.55 \mathrm{ng} / \mathrm{mL} / \mathrm{h}$ showed a sensitivity of $70.0 \%$ and specificity of $80.6 \%$. Interestingly, ARR $<95.4$ showed a sensitivity of $83.3 \%$ and specificity of $86.7 \%$, which were higher than those in PRA.
\end{abstract}

Conclusions: ARR decreased in patients with PCC, which was a more sensitive marker than PRA. Further study is necessary to understand the usefulness of this convenient marker in the detection of PCC.

Trial registration: This study was not registered because of the retrospective analysis.

Keywords: Pheochromocytoma, Adrenal incidentaloma, Renin, Aldosterone, ARR

\section{Background}

Pheochromocytoma (PCC) is a tumor arising from adrenomedullary chromaffin cells that commonly secret catecholamines (CAs), namely, adrenaline (Ad), noradrenaline (NA), and dopamine (DA). CAs can stimulate all major adrenergic receptors, including $\alpha 1, \alpha 2, \beta 1$, and $\beta 2$ receptors. Activation of $\alpha 1$ adrenergic receptors, located in vascular walls, induces

\footnotetext{
* Correspondence: fukuokah@med.kobe-u.ac.jp

'Division of Diabetes and Endocrinology, Kobe University Hospital, 7-5-2 Kusunoki-cho, Chuo-ku, Kobe 650-0017, Japan

Full list of author information is available at the end of the article
}

significant vasoconstriction, which chronically causes hypovolemia. Patients with PCC require surgical treatment to prevent fatal changes in hemodynamics [1]. Since life-threating problems, such as hypovolemic shock, can occur during the perioperative period, $\alpha 1$ blocker with salt loading should be administered to patients with PCC before surgery. These preoperative treatments can correct vasoconstriction and improve extracellular fluid volume [2]. Therefore, preoperative diagnosis and/or exclusion of PCC is quite important.

Measurement of plasma or urinary metanephrine (uMN) and normetanephrine (uNMN) levels is the gold standard in

(c) The Author(s). 2020 Open Access This article is licensed under a Creative Commons Attribution 4.0 International License, which permits use, sharing, adaptation, distribution and reproduction in any medium or format, as long as you give appropriate credit to the original author(s) and the source, provide a link to the Creative Commons licence, and indicate if changes were made. The images or other third party material in this article are included in the article's Creative Commons licence, unless indicated otherwise in a credit line to the material. If material is not included in the article's Creative Commons licence and your intended use is not permitted by statutory regulation or exceeds the permitted use, you will need to obtain permission directly from the copyright holder. To view a copy of this licence, visit http://creativecommons.org/licenses/by/4.0/ The Creative Commons Public Domain Dedication waiver (http://creativecommons.org/publicdomain/zero/1.0/) applies to the data made available in this article, unless otherwise stated in a credit line to the data. 
PCC screening. Because of its high sensitivity and specificity, it is quite useful in detecting and excluding pheochromocytoma [3-7]. However, a part of patients with PCC exhibit normal levels or within two-fold of the upper limit of normal levels [8]. Additionally, false-positive results for $\mathrm{uMN}$ or uNMN make it difficult to exclude PCC. Furthermore, in general practice, simple screening markers are needed to detect PCC from patients with hypertension.

Plasma renin activity (PRA) is increased in patients with PCC due to low circulating plasma volume and activation of $\beta-1$ adrenergic receptor signaling $[9,10]$. In the differential diagnosis of adrenal incidentaloma (AI) or secondary hypertension, plasma aldosterone concentration (PAC) and PRA are routinely measured in the screening of primary aldosteronism. However, limited data have been reported regarding PAC, PRA, and aldosterone renin ratio (ARR) in patients with PCC. This study aimed to determine the difference in PAC, PRA, and ARR between patients with PCC and those with subclinical Cushing's syndrome (SCS) or nonfunctioning adrenal adenoma (NFA).

\section{Methods}

\section{Subjects and study design}

This retrospective cross-sectional single-center study was approved by the ethics committee of Kobe University Hospital, and written informed consent was obtained from all subjects (IRB \#1351). We enrolled 83 consecutive patients with PCC, SCS, and NFA who were diagnosed and hospitalized in Kobe University Hospital between 2008 and 2014. We confirmed that all of these subjects had both PRA and PAC evaluated. Among them, patients who had received medication that can affect the renin-angiotensin aldosterone system, including aldosterone receptor blockers, diuretics, angiotensin converting enzyme (ACE) inhibitors, angiotensin receptor blockers $(\mathrm{ARB})$, and $\beta$-adrenergic blockers $(n=16)$, were excluded. The diagnosis of PCC was based on the Endocrine Society Guideline [11], which focused on increased uMN or uNMN levels, tumor demonstration by imaging test, and positive ${ }^{123} \mathrm{I}$ - metaiodobenzylguanidine (MIBG) scintigraphy. In all cases of PCC, the final diagnosis was histologically confirmed after surgery. The diagnosis of SCS and NFA was performed based on each guideline $[12,13]$.

\section{Hormone assays}

The PRA, PAC, and plasma CA levels were measured in the morning after overnight fasting in the supine position. After 24-h urinary excretion of fractionated MNs and CAs, all subjects were instructed to abstain from caffeinated foods and drinks for at least $48 \mathrm{~h}$. PRA, PAC, and plasma CA levels were measured by highperformance liquid chromatography (HPLC) (LSI
Medience Corporation, Tokyo, Japan), enzyme immunoassay (BML, Inc., Tokyo, Japan), and radioimmunoassay (LSI Medience Corporation, Tokyo, Japan), respectively. The intra- and inter assay coefficients of variations for each hormone assay were as follows: PRA, $<10$ and $<15 \%$; PAC, $<7.8$ and $<10.6 \%$; plasma $\mathrm{Ad},<4.08$ and $<2.23 \%$; $\mathrm{NA},<9.34$ and $<2.27 \%$; and DA $<8.96$ and $<2.89 \%$. uMN and CA levels were measured by HPLC (LSI Medience Corporation, Tokyo, Japan). The intra- and inter assay coefficients of variations for each hormone assay were as follows: urinary $\mathrm{Ad}$, $<6.21$ and $<6.35 \%$; urinary NA, $<4.09$ and $<3.82 \%$; urinary DA, $<5.32$ and $<4.46 \%$; uMN, $<1.4$ and $<6.2 \%$; and $\mathrm{uNMN}$, $<0.7$ and $<5.3 \%$.

\section{Statistical analysis}

Data were appropriately expressed as mean \pm standard deviation or median (interquartile range). These data were logarithmically transformed to normality before statistical analysis. We defined PCC as a control, and compared to SCS and NFA. Statistical comparisons among patients with PCC, SCS, and NFA were made using the Kruskal-Wallis test with post hoc Bonferroni's test or $x^{2}$ test followed by Tukey's honestly significant difference test, as appropriate. Receiver operating characteristic (ROC) curve analysis was performed to determine the optimal cutoff value in the diagnosis of PCC. $P$-values $<0.05$ were considered statistically significant. Statistical analyses were performed using with SPSS version 22.0 for Windows (SPSS Inc., Chicago, IL).

\section{Results}

\section{Patient characteristics}

As a result, we analyzed a total of 67 patients, consisting of 18 patients diagnosed with PCC, 18 patients with SCS, and 31 patients with NFA. The clinical characteristics of 67 patients (PCC; $n=18$, SCS; $n=18$, and NFA; $n=31$ ) are shown in Table 1 . Patients consist of 28 men and 39 women (women, $58.2 \%$ ), the mean age was $57 \pm$ 15 years, and the mean body mass index (BMI) was $23.1 \pm 4.1 \mathrm{~kg} / \mathrm{m}^{2}$. The mean size of the tumor was $3.3 \pm$ $2.6 \mathrm{~cm}$. Twenty-seven patients $(40.3 \%)$ had hypertension and treated with calcium channel blocker (CCB) and/or $\alpha$-blocker. Among the three groups, BMI in the PCC group was significantly lower than that in the SCS group $\left(21.0 \pm 3.3\right.$ vs. $\left.24.9 \pm 4.7 \mathrm{~kg} / \mathrm{m}^{2}, p=0.019\right)$. One patient with PCC was diagnosed with a familial syndrome, von Hippel-Lindau disease.

\section{Endocrinological findings}

Measurements of CA level and its metabolites in plasma and urine, adrenocorticotropin (ACTH), cortisol (F) in the morning, and F after 1-mg dexamethasone suppression test (DST), and dehydroepiandrosterone sulfate (DHEA-S), and imaging findings including tumor size 
Table 1 Clinical characteristics of patients with PCC, SCS, and NFA

\begin{tabular}{|c|c|c|c|c|c|c|c|}
\hline & Total & PCC & SCS & NFA & $p$ value & & \\
\hline & & & & & Kruskal-Wallis & PCC vs SCS & PCC vs NFA \\
\hline Number & 67 & 18 & 18 & 31 & & & \\
\hline Age (yr) & $57 \pm 15$ & $53 \pm 19$ & $57 \pm 14$ & $59 \pm 14$ & 0.404 & - & - \\
\hline Sex (males/females) & $28 / 39$ & $7 / 11$ & $6 / 12$ & $15 / 16$ & 0.564 & - & - \\
\hline Body Mass Index (kg/m²) & $23.1 \pm 4.1$ & $21.0 \pm 3.3^{*}$ & $24.9 \pm 4.7^{*}$ & $23.3 \pm 3.7$ & 0.023 & 0.019 & 0.256 \\
\hline Systolic blood pressure $(\mathrm{mmHg})$ & $127 \pm 19$ & $126 \pm 20$ & $132 \pm 12$ & $126 \pm 22$ & 0.372 & - & - \\
\hline Diastolic blood pressure $(\mathrm{mmHg})$ & $74 \pm 11$ & $72 \pm 9$ & $77 \pm 11$ & $73 \pm 12$ & 0.370 & - & - \\
\hline Antihypertensive Drugs (\%) & & & & & & & \\
\hline $\mathrm{CCB}$ & $25(37 \%)$ & $5(28 \%)$ & $8(44 \%)$ & $12(39 \%)$ & 0.572 & - & - \\
\hline a blocker & $7(10 \%)$ & $3(17 \%)$ & $2(11 \%)$ & $2(6 \%)$ & 0.527 & - & - \\
\hline
\end{tabular}

CCB Calcium channel blocker, $P C C$ pheochromocytoma, SCS subclinical cushing syndrome, NFA Non-functioning adrenal tumor Data are expressed as mean \pm S.D. ${ }^{*} p<0.05$ compared between group of PCC and SCS

and CT value are shown in Table 2. As expected, levels of $\mathrm{CA}$ and its metabolites in urine in patients with PCC were significantly higher than those in patients with SCS and NFA. Plasma ACTH level was lower in patients with SCS than those with PCC (9.7 (8.9 14.1) vs. $29.8(22.8$ $\sim 40.3) \mathrm{pg} / \mathrm{mL}, p<0.001$ ), and serum F level after 1 -mg DST was higher in patients with SCS than that in patients with PCC (6.1 (4.0 10.6) vs. $1.5(1.2 \sim 1.7) \mu \mathrm{g} / \mathrm{dL}$, $p<0.001)$.

\section{PRA, PAC, and ARR in PCC}

Next, PRA, PAC, and ARR in each group were compared (Fig. 1). PRA was significantly higher in patients with PCC than those with SCS and NFA $(2.1(1.3 \sim 2.8)$ vs. $0.7(0.5 \sim 1.8)$ and $0.9(0.6 \sim 1.4) \mathrm{ng} / \mathrm{mL} / \mathrm{h}, p=0.018$ and $p=0.025$; Fig. 1a). No difference in PAC was noted among the three groups (Fig. 1b). When PAC and PRA were plotted on the graph, the dots of PCC tended to present on the upper left part, suggesting that PRA was relatively higher than PAC (Fig. 1c). Intriguingly, ARR were significantly lower in patients with PCC than those in patients with SCS and NFA $(70.5(45.5 \sim 79.5)$ vs. 156.0 (92.9 194.5) and 114.9 (90.1 153.4), $p<0.001$ and $p<0.001$; Fig. 1d). Clinically, the diagnosis of PCC in patients showing either MN or NMN levels within two-fold of upper limit is challenge. Therefore, we investigated these subjects in our patients $(\mathrm{MN} ; n=7, \mathrm{NMN}$; $n=4$, Both; $n=1$, total; $n=10$ ). In these subjects, lower ARR was shown compared to SCS and NFA (PCC vs. SCS and NFA, $72.6(57.9 \sim 79.5)$ vs. $156.0(92.9 \sim 194.5)$

Table 2 Biochemical values and tumor characteristics in patients with PCC, SCS and NFA

\begin{tabular}{|c|c|c|c|c|c|c|}
\hline & \multirow[t]{2}{*}{ PCC } & \multirow[t]{2}{*}{ SCS } & \multirow[t]{2}{*}{ NFA } & \multicolumn{3}{|l|}{$p$ value } \\
\hline & & & & Kruskal-Wallis & PCC vs SCS & PCC vs NFA \\
\hline Plasma Ad (pmol/mL) & $0.13^{\mathbb{9}}(0.05-0.29)$ & $0.03(0.02-0.03)$ & $0.03^{9}(0.02-0.04)$ & 0.018 & 0.080 & 0.044 \\
\hline NA (pmol/mL) & $0.47^{* \Phi}(0.28-3.10)$ & $0.25^{*}(0.16-0.35)$ & $0.28^{\natural}(0.16-0.40)$ & 0.008 & 0.027 & 0.014 \\
\hline Urine Ad ( $\mu \mathrm{mol} /$ day) & $38.8^{* * a q}(10.6-98.6)$ & $6.13^{* *}(4.63-7.48)$ & $7.2^{9}(4.35-8.88)$ & $<0.001$ & $<0.001$ & $<0.001$ \\
\hline NA ( $\mu \mathrm{mol} /$ day $)$ & $356^{* * 99}(166-1004)$ & $99^{* *}(85-114)$ & $110^{99}(87-149)$ & $<0.001$ & $<0.001$ & $<0.001$ \\
\hline MN ( $\mu \mathrm{mol} /$ day) & $0.74^{* * .99}(0.13-2.23)$ & $0.09^{* *}(0.08-0.09)$ & $0.10^{919}(0.07-0.11)$ & $<0.001$ & $<0.001$ & $<0.001$ \\
\hline NMN ( $\mu \mathrm{mol} /$ day) & $1.89^{* * 99}(1.20-3.87)$ & $0.19^{* *}(0.16-0.22)$ & $0.19^{919}(0.16-0.30)$ & $<0.001$ & $<0.001$ & $<0.001$ \\
\hline Plasma ACTH (pg/mL) & $29.8(22.8-40.3)$ & $9.7(8.9-14.1)$ & $20.8(13.1-38.8)$ & $<0.001$ & $<0.001$ & 0.299 \\
\hline Serum $F(\mu \mathrm{g} / \mathrm{dL})$ & $15.1(12.3-16.9)$ & $13.6(12.2-16.4)$ & $15.4(12.7-17.0)$ & 0.741 & - & - \\
\hline DHEA-S $(\mu \mathrm{g} / \mathrm{dL})$ & $880(559-1104)$ & 371 (202-937) & $840(339-1191)$ & 0.562 & - & - \\
\hline F after $1 \mathrm{mg} \mathrm{DST}(\mu \mathrm{g} / \mathrm{dL})$ & $1.5(1.2-1.7)$ & $6.1(4.0-10.6)$ & $1.4(1.3-2.3)$ & $<0.001$ & $<0.001$ & 1.000 \\
\hline Tumor size $(\mathrm{cm})$ & $4.0^{919}(2.5-7.8)$ & $2.7(2.2-3.4)$ & $2.4^{919}(1.5-3.0)$ & 0.001 & 0.204 & 0.001 \\
\hline CT value $(H U)$ & $36^{* * 99}(27-42)$ & $15^{* *}(6-18)$ & $19^{19 \pi}(4-27)$ & $<0.001$ & $<0.001$ & 0.003 \\
\hline
\end{tabular}

Data are expressed as median (25-75th percentiles) ${ }^{*} p<0.05$ compared between group of PCC and SCS ${ }^{* *} p<0.005$ compared between group of PCC and SCS $" p<0.05$ compared between group of PCC and NFA "19 $p<0.005$ compared between group of PCC and NFA 

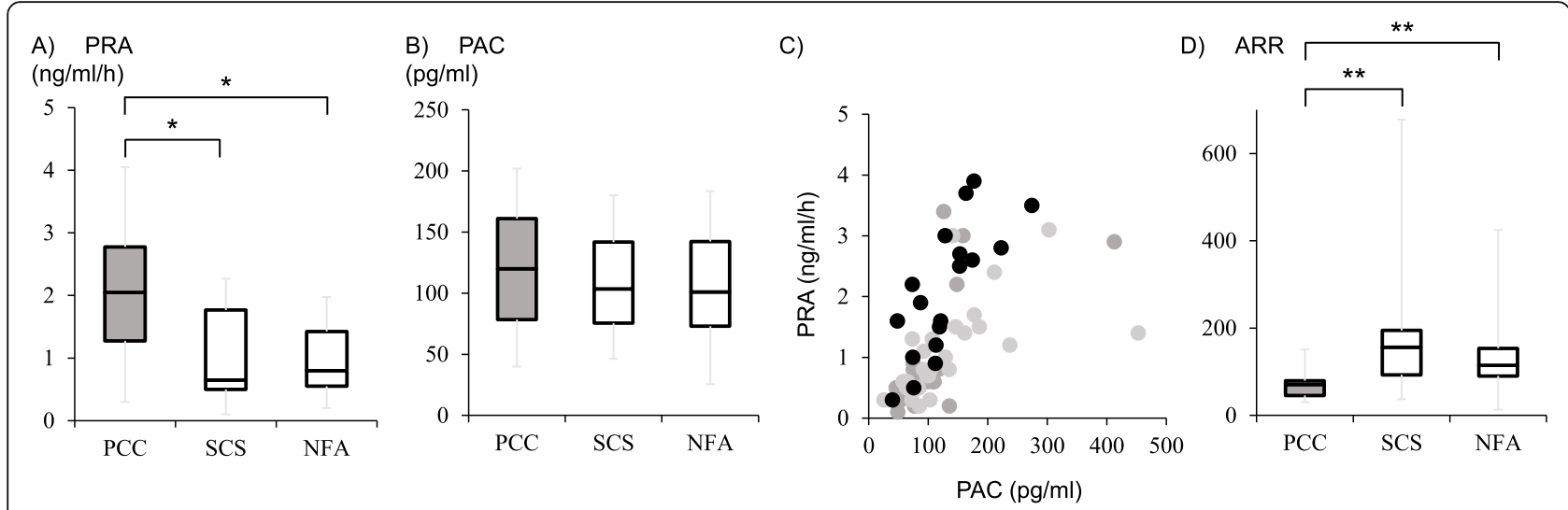

Fig. 1 Comparison of plasma renin activity; PRA (a), plasma aldosterone concentration; PAC (b), Scatter plot of PRA and PAC (c), and aldosterone renin ratio; ARR (d) in patients with PCC, SCS, and NFA. ARR values were significantly lower in PCC than those in SCS and NFA. Horizontal line, Median; box, $95 \% \mathrm{Cl}$. $P$ values are for the comparisons between all groups by Kruskal-Wallis, followed by Bonferroni's multiple comparison test between each of the two groups $\left({ }^{*} p<0.05,{ }^{* *} p<0.01\right)$. Black circle; PCC, dark gray circle; SCS, and light gray circle; NFA

and 114.9 (90.1 153.4), $p=0.008$, respectively), demonstrating the additive utility of ARR in PCC diagnosis.

ROC curve analysis to determine the optimal cutoff value in the diagnosis of PCC revealed that PRA of 1.45 $\mathrm{ng} / \mathrm{mL} / \mathrm{h}$ was optimal in the differentiation of PCC from SCS and NFA, with a sensitivity of $72.2 \%$ and specificity of $73.5 \%$ (Table 3a, Fig. 2a). ARR of 80.9 represented the optimal cutoff value with a sensitivity of $77.8 \%$ and specificity of $85.4 \%$ (Table 3a, Fig. 2c). ARR of 95.4 represented the optimal cutoff value for the differentiation of PCC from NFA, with a sensitivity of $83.3 \%$ and specificity of $86.7 \%$ (Table 3b, Fig. $2 \mathrm{~d}$ ), while uNMN or the sum of uMN and uNMN level showed a sensitivity of $100,78 \%$ and specificity of $75,93 \%$, respectively. To test whether ARR could be an additional marker to differentiate PCC from SCS and NFA, AUC (95\%CI) for ROC analysis was calculated, revealing that the AUC with uMN, uNMN, and ARR 0.944 (0.889-0.999) was higher than that with uMN and uNMN $0.872(0.766-$ 0.978), indicating the clinical utility of ARR in PCC diagnosis.

\section{Discussion}

In this study, we demonstrated that patients with PCC exhibited low ARR compared with those with SCS or NFA. ARR provided substantial sensitivity and specificity to discriminate PCC from other AIs. Increased ARR has generally been used in the screening of primary aldosteronism in patients with hypertension or AIs. Therefore, both PAC and PRA are commonly measured in the

Table 3 Receiver Operating Characteristic (ROC) curves

\begin{tabular}{|c|c|c|c|c|c|c|}
\hline & cutoff value & AUC & Sensitivity & Specificity & $p$ value & confidence interval \\
\hline \multicolumn{7}{|c|}{ (A) ROC curves for PCC from SCS and NFA. } \\
\hline PRA & 1.45 & 0.741 & 72.2 & 73.5 & 0.003 & $0.609-0.874$ \\
\hline ARR & 80.9 & 0.811 & 77.8 & 85.4 & $<0.001$ & $0.700-0.923$ \\
\hline uMN + uNMN & 0.146 & 0.872 & 77.8 & 92.6 & $<0.001$ & $0.766-0.978$ \\
\hline$P R A+u M N+u N M N$ & 0.132 & 0.935 & 88.9 & 82.6 & $<0.001$ & $0.876-0.993$ \\
\hline$A R R+u M N+u N M N$ & 0.213 & 0.944 & 94.4 & 86.7 & $<0.001$ & $0.889-0.999$ \\
\hline \multicolumn{7}{|c|}{ (B) ROC curves for PCC from NFA. } \\
\hline PRA & 1.55 & 0.751 & 70.0 & 80.6 & 0.004 & $0.603-0.899$ \\
\hline ARR & 95.4 & 0.858 & 83.3 & 86.7 & $<0.001$ & $0.764-0.983$ \\
\hline uMN + uNMN & 0.218 & 0.859 & 61.1 & 100 & $<0.001$ & $0.743-0.975$ \\
\hline PRA + uMN + uNMN & 0.819 & 0.946 & 94.4 & 83.3 & $<0.001$ & $0.890-1.003$ \\
\hline ARR + uMN + uNMN & 0.718 & 0.939 & 94.4 & 86.2 & $<0.001$ & $0.872-1.006$ \\
\hline
\end{tabular}

PRA plasma renin activity, $A R R$ aldosterone renin ratio

(A) $\mathrm{uMN}+\mathrm{uNMN} ;-2.738+8.019 \times \mathrm{uMN}-0.002 \times \mathrm{uNMN}, \mathrm{PRA}+\mathrm{uMN}+\mathrm{uNMN} ;-3.314+0.319 \times \mathrm{PRA}+8.111 \times \mathrm{uMN}-0.002 \times \mathrm{uNMN}, \mathrm{ARR}+\mathrm{uMN}+\mathrm{uNMN} ;-0.054$ $-0.028 \times$ ARR $+10.076 \times$ uMN $-0.004 \times$ uNMN

(B) $\mathrm{uMN}+\mathrm{uNMN} ; 2.203-6.983 \times \mathrm{uMN}+0.003 \times \mathrm{uNMN}, \mathrm{PRA}+\mathrm{uMN}+\mathrm{uNMN} ; 2.798-0.338 \times \mathrm{PRA}-7.032 \times \mathrm{uMN}-0.003 \times \mathrm{uNMN}, \mathrm{ARR}+\mathrm{uMN}+\mathrm{uNMN} ;-0.584+$ $0.031 \times$ ARR $-9.848 \times$ uMN $+0.005 \times$ uNMN 


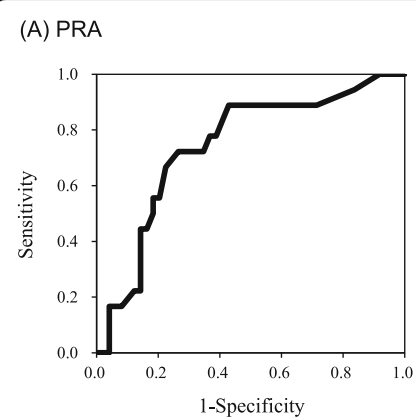

(B) PRA

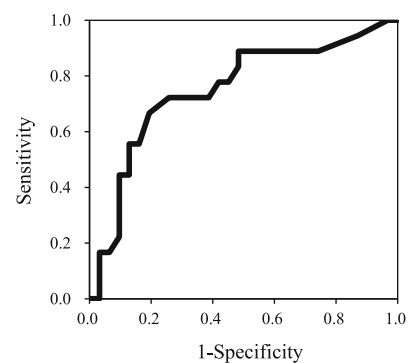

(C) ARR

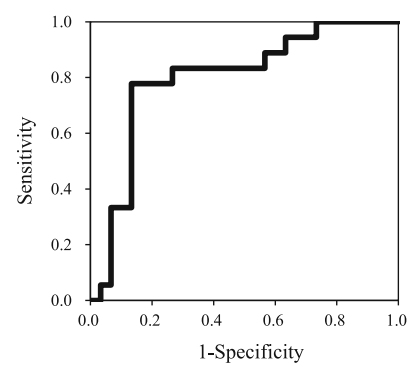

(D) ARR

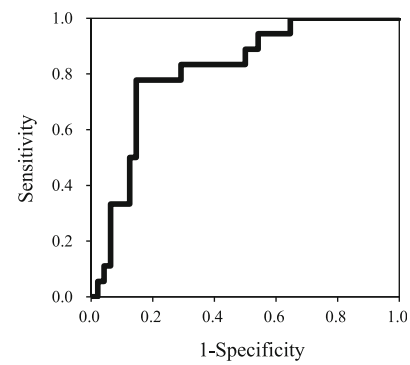

Fig. 2 a ROC curves of PRA for PCC from SCS and NFA. b ROC curve of PRA for PCC from NFA. $\mathbf{c}$ ROC curves of ARR for PCC from SCS and NFA. d ROC curve of ARR for PCC from NFA

routine diagnostic process in AIs and suspicion of secondary hypertension. The present data suggest that the application of ARR in the screening of PCC as in primary aldosteronism may be useful.

Measurement of plasma $\mathrm{MN}$ and $\mathrm{uMN}$ levels in the diagnosis of PCC shows excellent sensitivity (70.8$100.0 \%$ and $80.0-97.0 \%)$ and specificity $(79.4-97.6 \%$ and 69.0-95.1\%) [3-7]; therefore, it has been used as a gold standard. Indeed, in the present study, increased levels of $\mathrm{uMN}$ and $\mathrm{uNMN}$ provided the highest sensitivity $(80$ and $100 \%$, respectively) and specificity (100 and 75\%, respectively) in the diagnosis of PCCs with an area under the ROC curve of 0.875 and 0.950 , respectively. Thus, our data supports that measurements of $\mathrm{MN}$ level are recommended to screen PCC as demonstrated in the guidelines [11].

However, in clinical practice, there are some atypical AIs, such as PCCs without an increase in MN level and NFAs with a marginal increase in MN level [14]. In our series, we encountered a patient with NFA who showed increased plasma NA and uNMN levels (plasma NA, $0.63 \mathrm{pmol} / \mathrm{mL}$ [reference range, $0.15-0.57 \mathrm{pmol} / \mathrm{mL}$ ], uNMN, $0.186 \mu \mathrm{g} /$ day [reference range, $0.029-0.120 \mu \mathrm{g} /$ day]). Additionally, the patient had bilateral adrenal tumors $\left(2.8 \mathrm{~cm}\right.$ on the left, $1.9 \mathrm{~cm}$ on the right). ${ }^{123} \mathrm{I}$-MIBG scintigraphy demonstrated that accumulation was detected only in the left tumor. This patient underwent left adrenalectomy, and the final diagnosis was NFA. Preoperative endocrinological examination showed PRA of $0.2 \mathrm{ng} / \mathrm{mL} / \mathrm{h}$, PAC of $85 \mathrm{pg} / \mathrm{mL}$, and ARR of 425 . To exclude primary aldosteronism, we repeated the examination showed low PRA $(0.3 \mathrm{ng} / \mathrm{mL} / \mathrm{hr})$, with rather less PAC $(31.9 \mathrm{pg} / \mathrm{mL})$, suggesting this high ARR might be due to pseudo-aldosteronism rather than autonomous aldosterone hypersecretion. In fact, both PRA and PAC were not altered after adrenalectomy $(0.6 \mathrm{ng} / \mathrm{ml} / \mathrm{hr}$. and $57 \mathrm{pg} / \mathrm{mL}$, respectively). These data suggest that the evaluation of ARR provided additional information for accurate diagnosis. Furthermore, PCCs with normal MN levels have also been reported $[8,15]$. In such cases,
ARR may be helpful in the diagnosis of PCC as an additional marker. In fact, our data suggested ARR was useful in patients with PCC, who showed MN level within two-fold of upper limit.

It is well known that increased CA secretion in PCC causes chronic vasoconstriction, resulting in low circulating volume, which increases PRA [9]. Moreover, CAs directly stimulate renin secretion via a $\beta 1$-adrenergic receptor-mediated process [10] (Fig. 3), leading to increased PRA in PCCs (Fig. 1a). In contrast, there were no differences in PAC between the three groups (Fig. 1b). Interestingly, ROC curve analysis revealed that low ARR had higher sensitivity and specificity than increased PRA to discriminate PCC. These data suggest that aldosterone levels were relatively low despite the increased PRA in each case of PCC. Indeed, when PAC and PRA were plotted on the graph, the dots of PCC tended to present on the upper left part, suggesting that PAC was relatively lower than PRA in each case (Fig. 1c). There are several plausible explanations for this phenomenon. First, adrenomedullin (AM) is a peptide hormone that lowers blood pressure via vasodilation, which was originally isolated from PCC, and has been shown to induce renin resistance with ARR suppression [16]. Since plasma AM level is generally high in PCC [17], this could suppress ARR. Another possibility is atrial natriuretic polypeptide (ANP), whose plasma levels are generally increased in PCC [18]. ANP reduces angiotensin II-dependent aldosterone secretion that causes decreased ARR. Moreover, ANPdependent renal sodium excretion also leads to suppression of aldosterone production [18-20] (Fig. 3).

Regarding preoperative preparation of $\mathrm{PCC}$, it is critical to normalize circulating volume by $\alpha$-blocker administration to prevent perioperative complications [21]. In this aspect, it is important to have multiple biomarkers in the diagnosis or exclusion of PCC in addition to CAs preoperatively. Computed tomography (CT) value $<10 \mathrm{HU}$ is a useful marker to rule out PCC in AIs [22]. However, CT value is high in various pathological conditions, such as adrenocortical carcinoma and 


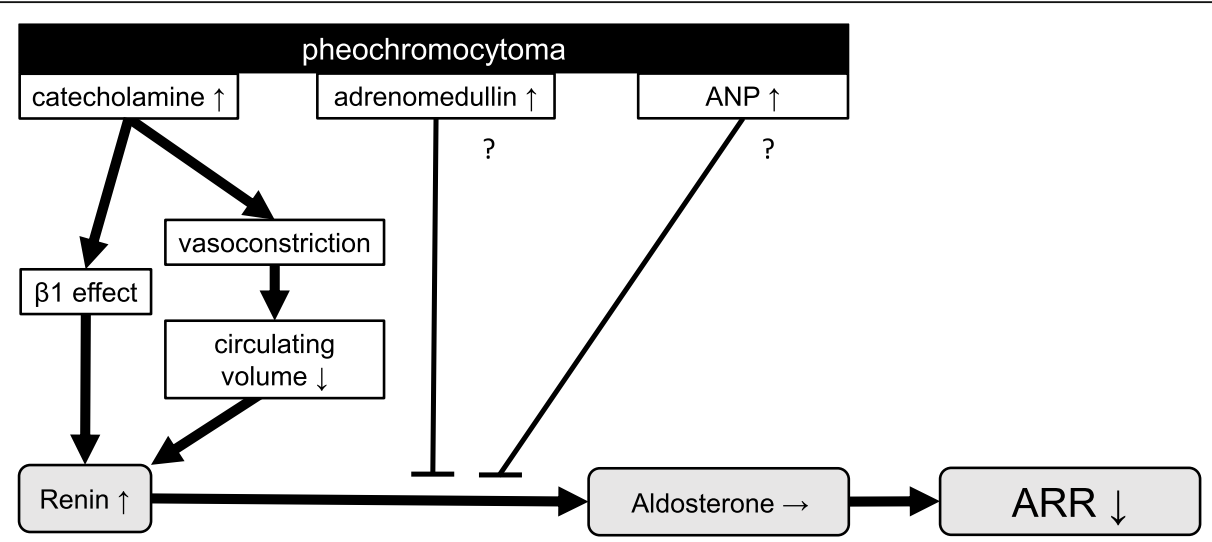

Fig. 3 The scheme of mechanistic hypothesis of the decreased ARR in PCC. Despite of the increased renin activity, patients with PCC showed a relatively low aldosterone levels than those in patients with SCS or NFA. This relatively low aldosterone in patients with PCC may be because of the increased secretion of adrenomedullin and ANP

metastatic adrenal mass. ${ }^{123}$ I-MIBG scintigraphy is also quite useful in the diagnosis of PCC with sensitivity of $85-88 \%$ and specificity of $84-100 \%$ [23-26]. However, the availability of this imaging equipment is limited especially in primary physicians. It is considered that the additional use of the convenient biomarker ARR in combination with the general information may help in obtaining a more accurate diagnosis.

There are several limitations in this study. This is a retrospective study, and the sample size is small, so it is necessary to validate these results in a large-scale cohort study. In addition, because there were few borderline $\mathrm{MN}$ and NMN values patients in this study, we cannot conclude whether ARR was really useful for these borderline cases. Further larger scale investigation is necessary to verify this point. Additionally, because some patients with NFA did not undergo surgery, we cannot completely exclude the possibility that PCC may be present in the NFA group. In this study, the patients taking $\alpha$-blocker was included. Since $\alpha$-blocker can restore the circulating plasma volume in patients with PCC, the effect of this drug on lowering PRA levels cannot be excluded. In this study, PCC patients taking $\alpha$-blocker included 3 subjects. These indicate that ARR can be used as an additional marker even if these drugs have been taken. Finally, because postoperative ARR could not be sufficiently studied, further longitudinal prolong evaluation is required to clarify whether this convenient index could be a useful biomarker at the post-operative state. To simplify the design, we restricted the patients in this study to $\alpha$-blocker and/or CCB users only. However, in the primary care clinic, it sometimes difficult to adjust the drugs for screening test. We think further investigation will be required whether this convenient ARR will also be useful in patients using other antihypertensive drugs such as $\beta$-blocker, diuretics, and ARB/ACEi. $\beta$ - blockers are expected to increase ARR and diuretics and ARB/ACEi decrease [27]. However, the antihypertensive drugs might be adjusted for screening of adrenaldependent hypertension including PA in patients with adrenal incidentalomas. We think this study could be helpful at least in these groups.

\section{Conclusion}

We demonstrated that patients with PCC exhibited low PAC/PRA than those with NFA or SCS, indicating that low ARR indicated the possibility of PCC. Further investigation is necessary to clarify whether this convenient index, "ARR," will help in the diagnosis of PCC.

\section{Abbreviations}

PRA: Plasma renin activity; PCC: Pheochromocytoma; ARR: Aldosterone renin ratio; PAC: Plasma aldosterone concentration; SCS: Subclinical Cushing's syndrome; NFA: Non-functioning adenoma; ROC: RECEIVER Operator Characteristic; CA: Catecholamine; Ad: Adrenaline; NA: Noradrenaline; DA: Dopamine; MN: Metanephrine; NMN: Normetanephrine; Al: Adrenal incidentaloma; ACE: Angiotensin converting enzyme; ARB: Angiotensin receptor blocker; MIBG: Metaiodobenzylguanidine; HPLC: High performance liquid chromatography; EIA: Enzyme immunoassay; RIA: Radioimmunoassay; BMI: Body mass index; CCB: Calcium channel blocker;

ACTH: Adrenocorticotropin; F: Cortisol; DST: Dexamethasone suppression test; DHEA-S: Dehydroepiandrosterone sulfate; CT: Computed tomography; AM: Adrenomedullin; ANP: Atrial natriuretic polypeptide

\section{Acknowledgements}

We thank our biostatisticians of the clinical \& translational research center at Kobe University Hospital for their excellent discussion and suggestions.

\section{Authors' contributions}

TY and HF designed the study. TY, HF, YH, OY, KY, RM HB, YO, and YH collected the data. TY, HF, YH, Gl, and $Y T$ analyzed the data. TY, HF, WO, and YT wrote the manuscript. All authors read and approved the final manuscript.

\section{Funding}

This work was supported in part by Grants-in-Aid for Scientific Research from the Japanese Ministry of Education Science, Culture, Sports, Science, and Technology (15 K09432 (HF), and 24790945 (HF)), Grants-in-Aid for Scientific 
Research (research on hypothalamic-hypophyseal disorders) from the Ministry of Health, Labor and Welfare of Japan.

\section{Availability of data and materials}

The datasets used and/or analysed during the current study are available from the corresponding author on reasonable request.

\section{Ethics approval and consent to participate}

This study was conducted in accordance with the Declaration of Helsinki and its amendments, and it was approved by the institutional review boards of the participating facilities (Kobe University Hospital ethical committee; IRB \#1351). Written informed consent was obtained from all participants.

\section{Consent for publication}

Not applicable.

\section{Competing interests}

The authors declare that they have no competing interests" in this section.

\section{Author details}

'Division of Diabetes and Endocrinology, Kobe University Hospital, 7-5-2 Kusunoki-cho, Chuo-ku, Kobe 650-0017, Japan. ${ }^{2}$ Division of Diabetes and Endocrinology, Kobe University Graduate School of Medicine, 7-5-2 Kusunoki-cho, Chuo-ku, Kobe 650-0017, Japan.

\section{Received: 14 January 2020 Accepted: 31 August 2020}

\section{Published online: 11 September 2020}

\section{References}

1. Pacak K. Preoperative management of the pheochromocytoma patient. J Clin Endocrinol Metab. 2007;92(11):4069-79.

2. Perry LB, Gould AB Jr. The anesthetic management of pheochromocytoma effect of preoperative adrenergic blocking drugs. Anesth Analg. 1972;51:3640.

3. Perry CG, Sawka AM, Singh R, Thabane L, Bajnarek J, Young WF Jr. The diagnostic efficacy of urinary fractionated metanephrines measured by tandem mass spectrometry in detection of pheochromocytoma. Clin Endocrinol. 2007;66(5):703-8

4. Lenders JW, Pacak K, Walther MM, Linehan WM, Mannelli M, Friberg P, et al. Biochemical diagnosis of pheochromocytoma: which test is best? JAMA 2002;287(11):1427-34.

5. Unger N, Pitt C, Schmidt IL, Walz MK, Schmid KW, Philipp T, et al. Diagnostic value of various biochemical parameters for the diagnosis of pheochromocytoma in patients with adrenal mass. Eur J Endocrinol. 2006; 154(3):409-17.

6. Hickman PE, Leong M, Chang J, Wilson SR, McWhinney B. Plasma free metanephrines are superior to urine and plasma catecholamines and urine catecholamine metabolites for the investigation of phaeochromocytoma. Pathology. 2009;41(2):173-7.

7. Grouzmann E, Drouard-Troalen L, Baudin E, Plouin PF, Muller B, Grand D, et al. Diagnostic accuracy of free and total metanephrines in plasma and fractionated metanephrines in urine of patients with pheochromocytoma. Eur J Endocrinol. 2010;162(5):951-60.

8. Kota SK, Kota SK, Panda S, Modi KD. Pheochromocytoma: an uncommon presentation of an asymptomatic and biochemically silent adrenal incidentaloma. Malays J Med Sci. 2012;19(12):86-91.

9. Skøtt O, Jensen BL. Cellular and intrarenal control of renin secretion. Clin Sci. 1993;84(1):1-10

10. Kopp U, DiBona GF. Interaction of renal beta 1-adrenoceptors and prostaglandins in reflex renin release. Am J Phys. 1983;244(4):F418-24.

11. Lenders JW, Duh QY, Eisenhofer G, Gimenez-Roqueplo AP, Grebe SK, Murad $\mathrm{MH}$. Et al; Endocrine Society. Pheochromocytoma and paraganglioma: an endocrine society clinical practice guideline. J Clin Endocrinol Metab. 2014; 99(6):1915-42.

12. Nieman LK, Biller BM, Findling JW, Newell-Price J, Savage MO, Stewart PM, et al. The diagnosis of Cushing's syndrome: an Endocrine Society clinical practice guideline. J Clin Endocrinol Metab. 2008;93(5):1526-40.

13. Zeiger MA, Thompson GB, Duh QY, Hamrahian AH, Angelos P, Elaraj D, American Association of Clinical Endocrinologists; American Association of Endocrine Surgeons, et al. American Association of Endocrine Surgeons. American Association of Clinical Endocrinologists and American Association of endocrine surgeons medical guidelines for the Management of Adrenal Incidentalomas: executive summary of recommendations. Endocr Pract. 2009;15(5):450-3.

14. Lee JA, Zarnegar R, Shen WT, Kebebew E, Clark OH, Duh QY. Adrenal incidentaloma, borderline elevations of urine or plasma metanephrine levels, and the "subclinical" pheochromocytoma. Arch Surg. 2007;142(9): 870-4.

15. Heavner MG, Krane LS, Winters SM, Mirzazadeh M. Pheochromocytoma diagnosed pathologically with previous negative serum markers. J Surg Oncol. 2015;112(5):492-5.

16. Charles CJ, Lainchbury JG, Nicholls MG, Rademaker MT, Richards AM, Troughton RW. Adrenomedullin and the renin-angiotensin-aldosterone system. Regul Pept. 2003;112(1-3):41-9.

17. Bravo EL. Evolving concepts in the pathophysiology, diagnosis, and treatment of Pheochromocytoma. Endocr Rev. 1994;15(3):356-68.

18. Hu W, Shi L, Zhou PH, Zhang XB. Plasma concentrations of adrenomedullin and atrial and brain natriuretic peptides in patients with adrenal pheochromocytoma. Oncol Lett. 2015;10(5):3163-70.

19. Atarashi K, Mulrow PJ, Franco-Saenz R, Snajdar R, Rapp J. Inhibition of aldosterone production by an atrial extract. Science. 1984;224(4652):992-4.

20. Nicholls MG. Hemodynamic and hormonal actions of adrenomedullin. Braz J Med Biol Res. 2004:37(8):1247-53.

21. Prys-Roberts C, Farndon JR. Efficacy and safety of doxazosin for perioperative management of patients with pheochromocytoma. World J Surg. 2002;26(8):1037-42

22. Buitenwerf E, Berends AMA, van Asselt ADI, Korteweg T, Greuter MJW Veeger NJM, et al. Diagnostic accuracy of computed tomography to exclude Pheochromocytoma: a systematic review, meta-analysis, and cost analysis. Mayo Clin Proc. 2019;94(10):2040-52.

23. Bhatia KS, Ismail MM, Sahdev A, Rockall AG, Hogarth K, Canizales A, et al. 1231-metaiodobenzylguanidine (MIBG) scintigraphy for the detection of adrenal and extraadrenal phaeochromocytomas: CT and MRI correlation. Clin Endocrinol. 2008:69(2):181-8.

24. Wiseman GA, Pacak K, O'Dorisio MS, Neumann DR, Waxman AD, Mankoff DA, et al. Usefulness of 123IMIBG scintigraphy in the evaluation of patients with known or suspected primary or metastatic pheochromocytoma or paraganglioma: results from a prospective multicenter trial. J Nucl Med. 2009;50(9):1448-54.

25. Fiebrich $H B$, Brouwers $A H$, Kerstens $M N$, Pijl ME, Kema IP, de Jong JR, et al. 6-[F-18]Fluoro-L-dihydroxyphenylalanine positron emission tomography is superior to conventional imaging with (123)I-metaiodobenzylguanidine scintigraphy, computer tomography, and magnetic resonance imaging in localizing tumors causing catecholamine excess. J Clin Endocrinol Metab. 2009:94(10):3922-30.

26. Milardovic R, Corssmit EP, Stokkel M. Value of 123I-MIBG scintigraphy in paraganglioma. Neuroendocrinology. 2010;91(1):94-100.

27. Mulatero P, Rabbia F, Milan A, Paglieri C, Morello F, Chiandussi L, et al. Drug effects on aldosterone/plasma renin activity ratio in primary aldosteronism. Hypertension. 2002;40(6):897-902.

\section{Publisher's Note}

Springer Nature remains neutral with regard to jurisdictional claims in published maps and institutional affiliations.

Ready to submit your research? Choose BMC and benefit from

- fast, convenient online submission

- thorough peer review by experienced researchers in your field

- rapid publication on acceptance

- support for research data, including large and complex data types

- gold Open Access which fosters wider collaboration and increased citations

- maximum visibility for your research: over $100 \mathrm{M}$ website views per year

At BMC, research is always in progress.

Learn more biomedcentral.com/submissions 